Since the majority of patients with SLE are double positive, differences between the two subspecificities of Ro (52 and 60) could not be analysed. On the other hand, no differences were found in cardiac conduction regarding the treatments received, the activity or damage indexes, or the analytical or clinical characteristics of the patients.

\begin{tabular}{|l|l|}
\hline \multicolumn{2}{|l|}{ Cumulative clinical manifestations (\%) } \\
\hline Articular & \multicolumn{2}{l|}{80} \\
\hline Cutaneous & 63 \\
\hline Leuco-lymphopenia & \multicolumn{1}{l}{42} \\
\hline Renal & 24 \\
\hline Serositis & 30 \\
\hline Neurologic & 9 \\
\hline Secondary antiphopholipid syndrome & 10 \\
\hline Secondary Sjögren syndrome & 10 \\
\hline Activity and damage indexes & \multicolumn{2}{|l}{} \\
\hline SLICC & $0,32 \pm 0,7$ \\
\hline SLEDAl in diagnosis & $7,97 \pm 4,2$ \\
\hline SLEDAl in inclusion & $1,82 \pm 2,48$ \\
\hline Analytical parameters & $51 \%$ \\
\hline Increased DNA & $207,86 \pm 357$ (UI/L) \\
\hline Average DNA & $39 \%$ \\
\hline Hxpocomplementemia & $31 \%$ \\
\hline Anti-Ro positive antibodies & \multicolumn{2}{|l}{} \\
\hline
\end{tabular}

Abstract AB0540 - Figure 1

Conclusions: The study results show that there are no differences in cardiac conduction according to the presence of anti-Ro antibodies in SLE patients. Thus, the cardiac screening in SLE patients with anti-Ro positive antibodies seems not helpful in clinical practice.

Disclosure of Interest: None declared

DOI: 10.1136/annrheumdis-2018-eular.5179

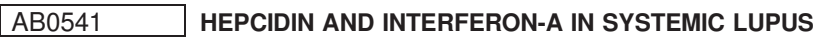 ERYTHEMATOSUS PATIENTS}

D. Archimandriti ${ }^{1}$, A.T. Tzallas ${ }^{2}$, T.-E. Memi ${ }^{1}$, P. Spyrou ${ }^{1}$, A.A. Drosos ${ }^{1}$, P. V. Voulgari ${ }^{1} .{ }^{1}$ Rheumatology Clinic, Department Of Internal Medicine, MEDICAL SCHOOL, UNIVERSITY OF IOANNINA; ' ${ }^{D}$ epartment of Computer Engineering, School of Applied Technology, Technological Educational Institute (TEI) of Epirus, Kostakioi, 47100, Arta, Greece, Ioannina, Greece

Background: Systemic lupus erythematosus (SLE) is a chronic autoimmune disease where interferon (IFN) $\alpha$, is considered to play a central role in its pathogenesis Anaemia of chronic disease (ACD) in SLE is common. Hepcidin may contribute to anaemia by limiting iron availability for erythropoiesis.

Objectives: The aim of the study was to evaluate INF- $\alpha$ and hepcidin levels in sera of anaemic and non-anaemic SLE patients.

Methods: This was a pilot study of SLE patients with established disease. Patients were divided as anaemic and non- anaemic according to the haemoglobin $(\mathrm{Hb})$ levels: $\mathrm{Hb}$ value $<13.5 \mathrm{gm} \%$ for men and $<11.5 \mathrm{gm} \%$ for females. ACD was defined according the levels of iron and ferritin. Serum hepcidin (the active 25 amino acid form) was measured using ELISA (Peninsula Laboratories International). IFN alpha was also measured using ELISA (eBioscience, affymetric). The inter-assay coefficient of variation was $<20 \%$ for both assays). All analyses were performed with IBMSPSS Statistics for Windows (version 21). Data are expressed as the mean \pm standard deviation (SD). Statistical analysis was performed using
Student's t-test for independent samples. The relationships between hepcidin level and all variables were analysed using two-tailed Pearson's correlation test. $P$ values less than 0.05 were considered significant.

Results: Forty SLE patients ( 36 women and 4 men) were studied. Demographic parameters were as follows: age $46.78 \pm 16.04$ years, disease duration 10.55 \pm 6.58 years. Levels of $\mathrm{Hb}$ were $12.49 \pm 1.28 \mathrm{~g} / \mathrm{dl}$. Levels of INF- $\alpha$ were 0.16 $\pm 0.47 \mathrm{pgr} / \mathrm{ml}$ while hepcidin levels were $2.54 \pm 2.63 \mathrm{ngr} / \mathrm{ml}$. When the patients were divided into anaemic (20 patients) and non-anaemic (20 patients) groups ( $\mathrm{Hb}: 11.41 \pm 0.56$ vs. $13.57 \pm 0.77 \mathrm{~g} / \mathrm{dl}, \mathrm{p}<0.001)$, patients with anaemia had lower disease duration $(9.75 \pm 6.16$ vs. $11.35 \pm 7.03$ years, $p=0.45$ ), lower levels of INF- $\alpha$ $(0.13 \pm 0.035$ vs. $0.19 \pm 0.036 \mathrm{pgr} / \mathrm{ml} \mathrm{p}<0.001)$ and higher hepcidin levels $(2.92$ \pm 2.9 vs. $2.17 \pm 2.35 \mathrm{ngr} / \mathrm{ml}, \mathrm{p}=0.37$ ) than the patients without anaemia. No correlation was observed between levels of hepcidin with all variables. There was also no correlation between hepcidin and INF- $\alpha$ levels.

Conclusions: INF- $\alpha$ does not seem to contribute in ACD pathogenesis in SLE patients and does not correlate with hepcidin levels in SLE patients. Further studies will clarify the role of INF- $\alpha$ in anaemia in SLE.

Disclosure of Interest: None declared

DOI: 10.1136/annrheumdis-2018-eular.5325

\section{AB0542 MULTIPLE SCLEROSIS IN PATIENTS WITH PRIMARY} SJÖGREN'S SYNDROME

E. Kaltsonoudis ${ }^{1}$, E. Pelechas ${ }^{1}$, S. Konitsiotis ${ }^{2}$, P.V. Voulgari ${ }^{1}$, A.A. Drosos ${ }^{1}$.

${ }^{1}$ Rheumatology Clinic, Department Of Internal Medicine; ${ }^{2}$ Neurology Clinic, MEDICAL SCHOOL, UNIVERSITY OF IOANNINA, Ioannina, Greece

Background: Imaging and histopathologic studies in patients with primary Sjögren's Syndrome (pSS) have demonstrated white matter lesions which are indistinguishable from those observed in multiple sclerosis (MS).

Objectives: The purpose of this study was to evaluate the frequency of MS in a cohort of patients with pSS.

Methods: One hundred and twenty-one patients with pSS had been evaluated and followed up in the outpatient Rheumatology Clinic at predefined times since 1994. All patients were classified according to the 2016 ACR-EULAR criteria for SS. During follow-up the clinical, laboratory and imaging findings were all recorded. In addition, Magnetic Resonance Imaging and electrophysiological studies as well as spinal fluid analysis were performed when indicated. The diagnosis of MS was based on the 2010 revised McDonald criteria.

Results: Seven patients were diagnosed as having MS. All patients with MS were female. Mean age at the time of MS diagnosis was $65.5 \pm 3.6$ years, while pSS has been diagnosed at the mean age of $54.4 \pm 3.2$ years. Mean time of MS development was approximately 10 years after the pSS diagnosis. pSS patients who developed MS had severe sicca symptoms without other extraglandular manifestations and had positive Ro (SSA) antibodies and a positive minor salivary gland biopsy. pSS patients with MS development were treated appropriately in the Neurology department with biological medications with some improvement of the sicca symptoms.

Conclusions: We found that $5.8 \%$ of pSS patients as having MS. This percentage of patients clearly indicates the possibility for the coexistence of a second autoimmune disease with similar if not common pathogenetic mechanisms. Thus patients with pSS should be evaluated carefully and screened appropriately for MS when indicated.

Disclosure of Interest: None declared

DOI: 10.1136/annrheumdis-2018-eular.3398

\section{AB0543 CORRELATION BETWEEN SYSTEMIC LUPUS ERYTHEMATOSUS DISEASE ACTIVITY AND OCULAR SIGNS IN OPHTHALMOLOGICALLY ASYMPTOMATIC PATIENTS}

S.A. Fouad ${ }^{1}$, S.M. Esmat Mahmoud Ali ${ }^{2}$, A.R.L. Rezk Alnaggar ${ }^{1}$, S. Mahfouz ${ }^{1}$, M. Essam ${ }^{1}, \mathrm{H}$. El-Gendy ${ }^{1} .{ }^{1}$ Internal Medicine Department, ${ }^{2}$ Ophthalmology, Kasr Al Einy hospital, Cairo University, Giza, Egypt

Background: Systemic lupus erythematosus (SLE) is an autoimmune disease involving different organs and systems. Ocular manifestations of lupus may manifest as a presenting feature of the disease or as a complication that can be sight threatening. Almost any part of the eye and visual pathway can be affected by inflammatory or thrombotic processes yet ophthalmological assesment in those patients may be delayed.

Objectives: Detection of various ocular pathologies in ophthalmologically asymptomatic SLE patients using Optical Coherence Tomography (OCT), Fundus Fluorescein angiography (FFA), and fundus examination, in addition to studying the 